\title{
Empreendimentos econômicos solidários acompanhados pela Incubadora Tecnológica de Cooperativas Populares de uma instituição de Ensino Superior em Minas Gerais
}

\author{
Pablo Luiz Martins ${ }^{1}$ \\ Daniela Aparecida Sandim² \\ Maria do Carmo Santos Neta ${ }^{3}$
}

\begin{abstract}
Resumo
Embora cada vez mais presente na sociedade, a economia solidária, que serve de base para as Incubadoras Tecnológicas de Cooperativas Populares (ITCP's) desenvolverem seus trabalhos e auxiliarem diversos Empreendimentos Econômicos Solidários (EES), é um tema ainda pouco debatido. A ITCP/UFSJ conta com discentes de cursos variados da UFSJ. Dentre estes cursos está o de Ciências Contábeis. Desta forma, dois empreendimentos foram escolhidos para ser estudados neste trabalho: a Associação de Catadores de Materiais Recicláveis de São João Del-Rei (ASCAS) e a Associação dos Artesãos e Empreendedores de Economia Familiar (ASAENFA). Os empreendimentos têm obrigações legais e fiscais a serem cumpridas, porém poucos são os que possuem conhecimento sobre esse fato. O presente trabalho tem como objetivo identificar a importância da ITCP/UFSJ, dos discentes da graduação de Ciências Contábeis e da contabilidade nos empreendimentos estudados, além de tratar um pouco mais sobre Economia Solidária e sobre as obrigações legais e fiscais desses empreendimentos. A fim de atingir tal objetivo, utilizou-se um referencial teórico e aplicou-se um questionário para os associados, o contador da ASCAS e para o coordenador da ASAENFA. De fato, perceber-se-á que a Economia Solidária é um tema que traz dúvidas, mas é praticada dentro das associações, e que, apesar da contabilidade trazer dificuldades para os associados, ela foi avaliada como sendo fundamental para o desenvolvimento dessas associações. Além disso, foi constatado que as obrigações fiscais e legais não são do conhecimento de todos, mas que as associações estão com os documentos em dia, exceto as demonstrações contábeis.
\end{abstract}

Palavras-chave: Economia Solidária. Incubadoras Tecnológicas de Cooperativas Populares. ITCP's. Contabilidade.

\begin{abstract}
Solidarity Economy is an issue that is still under discussion, but increasingly present in society, which serves as the basis for the Technological Incubators of Popular Cooperatives (ITCP's) to develop their work and assist in various Economic Solidarity Projects (EES). The ITCP / UFSJ counts on students of varied courses of the UFSJ. Among these courses is the Accounting Sciences, in this way two projects were chosen to be studied in this work: the Association of Collectors of Recyclable Materials of São João del-Rei (ASCAS) and the Association of Artisans and Entrepreneurs of Family Economy (ASAENFA). The enterprises have legal and fiscal obligations to be fulfilled, but few are those who have knowledge about this fact. This paper aims to identify the importance of the ITCP / UFSJ, the undergraduate students of Accounting Sciences and accounting in the projects studied, as well as to discuss a little more about Solidarity Economy and about the legal and fiscal obligations of these enterprises. In order to achieve this objective, a theoretical reference was used and a questionnaire was applied

\footnotetext{
${ }^{1}$ Doutorando em Ciências da Linguagem. Professor da Universidade Federal de São João Del Rei (UFSJ). pablo@ufsj.edu.br

${ }^{2}$ Graduada em Ciências Contábeis. danisandim@hotmail.com

${ }^{3}$ Doutora em Educação. Professora da Universidade Federal de São João del-Rei. sneta@ufsj.edu.br
} 
to ASCAS members and accountant and to the ASAENFA coordinator. In fact, it will be noticed that Solidarity Economy is a questionable question, but it is practiced within the associations, and that, despite accounting difficulties for members, it was evaluated as being fundamental for the development of associations. In addition, it was found that tax and legal obligations are not known to all, but the associations are with the documents in the day, except the financial statements.

Keywords: Solidarity Economy. Technological Incubators of Popular Cooperatives. ITCP'S. Accounting.

\section{Introdução}

O capitalismo apresenta um cenário de competitividade e estreita troca de informações entre indivíduos e empresas. Diante disso, muitas pessoas não conseguem se inserir nesse mercado e buscam novas alternativas de geração de renda. Uma dessas alternativas é a economia solidária, que tem como características principais a autogestão e o cooperativismo.

Diante deste cenário, surgem as Incubadoras Tecnológicas de Cooperativas Populares (ITCP's), que se baseiam nas características da economia solidária e atuam em ações de ensino, pesquisa e extensão universitária, buscando articular várias áreas do conhecimento com grupos que, por algum motivo, não estão inseridos no mercado de trabalho, mas desejam melhoria da qualidade de vida.

As atividades promovidas pelas ITCP's são voltadas para a inserção de trabalhadores, desempregados ou indivíduos vinculados a atividades informais, as quais, por meio da organização do trabalho em empreendimentos produtivos de base solidária, buscam a geração de trabalho e renda. A metodologia de incubação é construída de acordo com o contexto em que a universidade está inserida e de acordo com as demandas de cada empreendimento.

No Brasil, as ITCP's surgiram na Universidade Federal de São João Del-Rei (UFSJ), criada em 1999 e, logo após, passando a integrar a Rede de ITCP's formada por incubadoras universitárias brasileiras com o objetivo de disseminar a Economia Solidária e propiciar uma interação entre as incubadoras. Desde sua criação, a ITCP/UFSJ apoia o desenvolvimento da economia solidária na região e busca atender aos setores marginalizados economicamente.

Os discentes geralmente realizam visitas semanais nos empreendimentos e buscam auxiliar os trabalhadores na melhor forma de se organizarem. Este estudo observará dois empreendimentos incubados pela ITCP/UFSJ, a Associação de Catadores de Materiais 
Recicláveis de São João Del-Rei (ASCAS) e a Associação dos Artesãos e Empreendedores de Economia Familiar (ASAENFA), visando identificar a importância dos discentes de Ciências Contábeis para os empreendimentos incubados, além da importância da ITCP/UFSJ como um todo para as associações.

Sabe-se que a contabilidade é de grande importância para qualquer entidade. $\mathrm{Na}$ economia solidária, a contabilidade segue as obrigações legais e fiscais aplicadas ao Terceiro Setor. Porém, são muitos os empreendimentos que não estão conscientizados de suas obrigações, e, com isso, possuem muitos débitos com a União, os Estados, o Distrito Federal e os Municípios, prejudicando o seu desenvolvimento. Portanto, este estudo busca também identificar o papel e a importância da contabilidade nos empreendimentos estudados e quais obrigações legais e fiscais Ihes são aplicadas.

\section{A Economia Solidária}

O crescimento desenfreado do capitalismo, associado ao desenvolvimento tecnológico, gerou a precariedade do trabalho, das condições de vida e o desemprego de um grande contingente de trabalhadores. Como resultado, o cenário do mundo do trabalho passou a ser o de muitos trabalhadores instáveis, desempregados, excluídos e pauperizados. Surge, então, nesse contexto, a chamada "economia solidária" como uma alternativa de gerar emprego e renda para esses grupos socialmente excluídos.

Segundo Singer (2002), a economia solidária não veio somente para complementar a economia capitalista, pois, se assim o fosse, aquela só teria perspectivas de desenvolvimento quando o capitalismo estivesse em crise. Sendo assim, trata-se de uma nova economia, que alia a produção industrial à organização comunitária da vida social.

A definição de economia solidária não é única, apresentando divergências teóricas por parte de vários autores. No entanto, não é intuito deste tópico ser preciso em relação às definições, e sim apresentar ideias que contribuam para um entendimento do que venha a ser o termo "economia solidária". 
Singer (2002) afirma que:

A Economia Solidária é ou poderá ser mais do que mera resposta à incapacidade do capitalismo de integrar em sua economia todos os membros da sociedade desejosos e necessitados de trabalhar. Ela poderá ser o que em seus primórdios foi concebida para ser: uma alternativa superior ao capitalismo. Superior não em termos econômicos estritos, ou seja, que as empresas solidárias regularmente superariam suas congêneres capitalistas, oferecendo aos mercados produtos ou serviços melhores em termos de preço e/ou qualidade. A Economia Solidária foi concebida para ser uma alternativa superior por proporcionar às pessoas que a adotam, enquanto produtoras, poupadoras, consumidoras etc., uma vida melhor (SINGER, 2002, p. 114).

Percebe-se que um dos objetivos da economia solidária é pensar no bem-estar da sociedade, sendo uma estratégia para o desenvolvimento sustentável e solidário, com geração de trabalho e distribuição de renda. Tendo como fundamento o desenvolvimento solidário, duas características importantes dessa economia são a autogestão e o cooperativismo.

Por autogestão entende-se que não há patrões, as decisões são tomadas em conjunto e buscam o melhor para o empreendimento como um todo. O cooperativismo caracteriza-se por ser mais democrático, justo, e buscar, numa determinada sociedade, o alcance de objetivos comuns. Baseadas na autogestão e no cooperativismo, existem cooperativas e associações populares, os chamados Empreendimentos Econômicos Solidários (EES), que buscam satisfazer as necessidades econômicas, sociais e culturais comuns, ou seja, as pessoas se unem, voluntariamente, com objetivos comuns.

\subsection{Importância da Contabilidade na Economia Solidária}

A contabilidade é de grande importância em qualquer tipo de entidade. É através dela que se tem um controle sobre o patrimônio da entidade, das suas receitas e das suas despesas. O objetivo da contabilidade para ludícibus e Marion (2007, p. 53) é “[...] fornecer informação estruturada de natureza econômica, financeira e, subsidiariamente, física, de produtividade e social, aos usuários internos e externos à entidade objeto da contabilidade". 
Os usuários da informação contábil são os que se interessam pelas demonstrações contábeis da entidade com o intuito de auxiliarem na tomada de decisões. Os principais usuários das demonstrações contábeis são os investidores, os empregados, os credores por empréstimos, os fornecedores e outros credores comerciais; os clientes, o governo e suas agências e o público em geral.

A contabilidade deve atender aos seus diversos usuários e fornecer informações úteis que auxiliem na tomada de decisão. Os Empreendimentos Econômicos Solidários (EES) são usuários da contabilidade e necessitam ter suas demandas atendidas, porém encontram dificuldades em relação à contabilidade.

Almeida (2006, p. 59) destaca que os modelos de informação contábil conhecidos estão estruturados "[...] de forma a atender grupos mais ou menos homogêneos de usuários, isto é, há uma padronização de informações usadas por todos os usuários" e, muitas vezes, não analisam as suas características. Os EES têm peculiaridades específicas, principalmente pelo fato de seus trabalhadores possuírem poucos conhecimentos sobre contabilidade.

Para a informação contábil ser útil, ela precisa ser confiável, tempestiva, comparável e compreensível por seus usuários. Nesse aspecto, os modelos padronizados não são compreensíveis aos usuários dos EES. Se não fossem essas peculiaridades específicas, a Contabilidade das Cooperativas e a Contabilidade Societária, regidas pela NBC T 10.8 do Conselho Federal de Contabilidade e pela Lei das Sociedades Anônimas (6.404/76), seriam suficientes. Porém essas normas não satisfazem às necessidades dos EES e, com isso, não há normas brasileiras de contabilidade (NBC) voltadas aos EES.

É comum que os EES não tenham em dia demonstrações contábeis e débitos com a União, com os Estados, com o Distrito Federal e com os Municípios. Muitas vezes, são necessárias certidões negativas de débitos e de relatórios contábeis para que esses empreendimentos recebam recursos visando a seu desenvolvimento. Os EES têm obrigações legais e fiscais para a continuidade de seu trabalho. A contabilidade não deve ser complexa, mas simplificada, de modo que os ajude a cumprir suas obrigações e seja suficiente para o entendimento de seus usuários. 


\subsubsection{Aspectos Legais e Fiscais}

A economia solidária difere do Terceiro Setor por este ter o caráter filantrópico e de prestação de serviços, e aquela possuir o caráter de geração de renda para as pessoas socialmente excluídas, visando sua inserção na sociedade e uma melhor qualidade de vida. Apesar das diferenças existentes entre eles, os aspectos legais e fiscais na economia solidária são iguais aos aplicados no Terceiro Setor. Há imunidades, isenções, obrigações acessórias e demonstrações contábeis previstas para o Terceiro Setor, e, portanto, também para a economia solidária. Porém muitas entidades não possuem conhecimentos sobre o assunto, e, com isso, várias obrigações legais e fiscais estão em débito, o que prejudica o empreendimento.

As imunidades estão previstas na Constituição Federal de 1988 (BRASIL, 2016) e somente devem ser alteradas mediante alteração na Constituição. De acordo com CF/88, art. 150, inc. VI e alínea c, é vedado à União, aos Estados, ao Distrito Federal e aos Municípios instituir impostos sobre o patrimônio, renda ou serviços das entidades sindicais dos trabalhadores, das instituições de educação e de assistência social, sem fins lucrativos, atendidos os requisitos da lei. O artigo 195 , $\S^{\circ}$ - da $C F / 88$, traz ainda que são isentas de contribuição para a seguridade social as entidades beneficentes de assistência social que atendam às exigências estabelecidas em lei.

Os impostos por esfera de governo que não podem ser cobrados de entidades imunes previstos no art. 150 da CF/88 são:

- Federal: Imposto de Renda (IR), Imposto sobre Produtos Industrializados (IPI), Imposto Territorial Rural (ITR), Imposto sobre Exportação (IE), Imposto sobre Importação (II) e Imposto sobre Operações Financeiras (IOF).

- Estadual: Imposto sobre a Circulação de Mercadorias e sobre Prestação de Serviços (ICMS), Imposto sobre a Propriedade de Veículos Automotores (IPVA) e Imposto sobre a Transmissão Causa Mortisou Doação de Bens e Direitos (ITCD).

- Municipal: Imposto sobre Serviços de Qualquer Natureza (ISS), Imposto sobre a Propriedade Territorial Urbana (IPTU) e Imposto sobre a Transmissão Inter Vivos de Bens Imóveis. 
As isenções são previstas através de Leis Ordinárias e ocorrem quando uma situação ou alguém são desobrigados ao pagamento de certos impostos ou taxas. A CF/88, art. 151 inc. III, diz que é vedado à União instituir isenções de tributos da competência dos Estados, do Distrito Federal ou dos Municípios. Portanto, as isenções são de competência de cada ente federativo, o que torna difícil apontar todos os casos. De acordo com o Código Tributário Nacional (CTN), art. 113, a obrigação tributária é principal ou acessória.

§1으 A obrigação principal surge com a ocorrência do fato gerador, tem por objeto o pagamento de tributo ou penalidade pecuniária e extingue-se juntamente com o crédito dela decorrente.

§ 2o A obrigação acessória decorre da legislação tributária e tem por objeto as prestações, positivas ou negativas, nela previstas no interesse da arrecadação ou da fiscalização dos tributos.

§ 3으 A obrigação acessória, pelo simples fato da sua inobservância, converte-se em obrigação principal relativamente à penalidade pecuniária.

Analisando ainda o CTN (CTNSRF, 2016), os artigos 114 e 115 trazem os fatos geradores da obrigação principal e acessória:

Art. 114. Fato gerador da obrigação principal é a situação definida em lei como necessária e suficiente à sua ocorrência.

Art. 115. Fato gerador da obrigação acessória é qualquer situação que, na forma da legislação aplicável, impõe a prática ou a abstenção de ato que não configure obrigação principal.

Pode-se perceber que na obrigação principal surge o fato gerador, e o contribuinte tem o dever do pagamento do tributo. A obrigação acessória não tem caráter pecuniário, mas o dever de informar ao fisco as atividades da entidade. As principais obrigações acessórias que o Terceiro Setor deve informar são a Declaração de Débitos e Créditos Tributários Federais (DCTF), a Relação Anual de Informações Sociais (RAIS), a Escrituração Contábil Fiscal (ECF), o Guia de Recolhimento do Fundo de Garantia por Tempo de Serviço e Informações à Previdência Social (GFIP) e o Cadastro Geral de Empregados e Desempregados (CAGED).

A DCTF é uma obrigação das indústrias, do comércio, de serviços e do Terceiro Setor, exceto aos enquadrados no Simples Nacional e no Microempreendedor Individual (MEI). É uma declaração mensal e pretende informar os débitos e os créditos tributários federais. 
A RAIS é uma declaração anual e tem objetivo de informar o número de empregados mantidos no estabelecimento. Se não houver empregados, ou se o estabelecimento permaneceu inativo, deve-se informar a RAIS negativa.

A ECF está em vigor desde do ano-calendário de 2014 e veio para substituir a Declaração de Informações Econômico-Fiscais da Pessoa Jurídica (DIPJ). É uma obrigação anual, que deve informar as operações que compõem a base de cálculo e o valor apurado do Imposto de Renda de Pessoa Jurídica (IRPJ) e da Contribuição Social sobre o Lucro Líquido (CSLL).

A GFIP é a declaração que pode gerar a Guia de Recolhimento do FGTS (GRF). É uma obrigação mensal e deve ser informada por todas as empresas sujeitas ao recolhimento do FGTS, contribuições e/ou informações à Previdência Social. Mesmo as entidades que não possuem recolhimento do FGTS estão obrigadas à entrega da GFIP, devendo-se entregar uma declaração no início das atividades, informando que não há empregados. Empresa sem movimentação de empregados não precisa prestar essa informação todo mês. O CAGED é obrigatório a todas as entidades que movimentaram empregados regidos pela Consolidação das Leis do Trabalho (CLT). É uma obrigação a ser cumprida todo mês em que houver movimentação de empregados.

As obrigações acessórias devem ser informadas até mesmo pelas entidades imunes ou isentas. A não declaração pode provocar incidência de multas. Com declarações atrasadas, não são emitidas as certidões negativas de débitos, necessárias, muitas vezes, para o recebimento de recursos para as entidades.

Com os conceitos citados sobre obrigação principal e acessória, pode-se entender que os EES não têm a obrigação de pagamento do tributo, e, sim, da sua informação ao fisco para que os empreendimentos fiquem em dia com suas declarações.

De acordo com as normas do Conselho Federal de Contabilidade (CFC), as demonstrações contábeis para o Terceiro Setor são o Balanço Patrimonial, a Demonstração do Superávit ou Déficit do Exercício, a Demonstração das Mutações do Patrimônio Líquido e a Demonstração das Origens e Aplicações de Recursos. Outra demonstração que também pode ser feita é a Declaração do Fluxo de Caixa.

O Balanço Patrimonial, de acordo com a NBC T 3, é "[...] de demonstração contábil destinada a evidenciar, quantitativa e qualitativamente, numa determinada data, o 
Patrimônio e o Patrimônio Líquido da entidade". Sobre a Demonstração do Resultado do Exercício (DRE), Campiglia (1997) diz que:

[...] tem por finalidade evidenciar o resultado (lucro ou prejuízo) periódico da instituição e os fatores negativos (custos e despesas) e positivos (ganhos e rendimentos) que entram na composição desse resultado, representados por saldos das contas a que se referem (CAMPIGLIA, 1997, p. 49).

Para organizações do Terceiro Setor, o lucro ou o prejuízo na DRE é chamado de superávit ou de déficit. Em relação à Demonstração das Mutações do Patrimônio Líquido (DMPL), Nascimento e Olak (2000, p. 11) dizem que, “[...] em linhas gerais, essa demonstração explicará como e por que as diversas contas do patrimônio líquido modificam-se durante o período".

A Demonstração das Origens e Aplicações de Recursos (DOAR), de acordo com Marion (1998, p. 407), “[...]explica a variação do Capital Circulante Líquido (Capital de Giro Próprio ou Capital de Giro Líquido) ocorrida de um ano para o outro. Ajuda-nos a compreender como e por que a Posição Financeira mudou de um exercício para outro". Marion (1998, p. 381) também conceitua a Demonstração do Fluxo de Caixa (DFC) como “[...] a origem de todo dinheiro que entrou no Caixa, bem como a aplicação de todo o dinheiro que saiu do Caixa em determinado período, e, ainda, o Resultado do Fluxo Financeiro".

Como forma de ajudar os Empreendimentos Econômicos Solidários (EES), as universidades brasileiras desenvolvem um trabalho baseado nas características da economia solidária, visando ao desenvolvimento tanto das cooperativas e associações populares quanto dos professores, alunos, funcionários e população em geral. Então, surgiram as Incubadoras Tecnológicas de Cooperativas Populares (ITCP's).

\section{Incubadoras Tecnológicas de Cooperativas Populares (ITCP's)}

Em 1992, houve um programa contra a fome e a miséria, denominado "Ação de Cidadania", idealizado pelo sociólogo Herbert de Souza (Betinho). A proposta deste programa consistia em buscar alternativas de trabalho e renda para os desempregados e excluídos socialmente. Outra situação semelhante aconteceu na Fundação Oswaldo Cruz. Professores fizeram um estudo na favela vizinha à Fundação e concluíram que o problema 
da violência era a falta de emprego. Com isso, eles decidiram montar uma cooperativa com os desempregados da favela, denominada Cooperativa de Manguinhos, que foi uma experiência bem-sucedida (BOCAYUVA, 2001).

As situações descritas acima inspiraram professores e estudantes da Coordenação de Programas de Pós-Graduação da Engenharia (COPPE) da Universidade Federal do Rio de Janeiro (UFRJ) a criarem a primeira Incubadora Tecnológica de Cooperativas Populares, visando à criação de novas cooperativas e a utilização dos conhecimentos adquiridos na universidade no auxílio e apoio a essas novas cooperativas (OLIVEIRA; ALVES; PONTELO, 2007).

Diante do surgimento de várias ITCP's, houve a criação, em 1999, da Rede de Incubadora de Cooperativas Populares, formada por incubadoras de universidades brasileiras, com o objetivo de realizar trocas de experiências entre as incubadoras e os cooperativados. Alguns princípios que norteiam a Rede de ITCP's, de acordo com o seu estatuto, são disseminar conhecimentos sobre cooperativismo e autogestão, trabalhar na consolidação e integração das cooperativas populares e estimular a cooperação entre incubadoras, a criação de incubadoras tecnológicas de cooperativas populares e o relacionamento com outras redes que possuam objetivos comuns.

As ITCP's seguem os princípios da rede, porém a metodologia de incubação adaptarse-á ao ambiente em que cada universidade está inserida e à demanda de cada região. Ao falar de incubação, Bocayuva (2001) a entende como:

\footnotetext{
Um processo que visa apoiar a construção associativa e legal- formal, o acesso ao mercado, a elaboração de projetos, a definição de processo e produto, o acompanhamento e a capacitação gerencial, a administração, o planejamento, a controladoria, a contabilidade e outras áreas necessárias ao sucesso do empreendimento (BOCAYUVA, 2001, p. 8).
}

Pode-se entender que as incubadoras buscam a inserção da população marginalizada no processo produtivo, atuam em ações de ensino, pesquisa e extensão universitária e conciliam várias áreas para uma melhor organização e apoio às cooperativas e às associações, buscando sempre uma melhor qualidade de vida para os cooperativados e associados. 
Singer (2002) destaca o trabalho das ITCP's:

As ITCPS são multidisciplinares, integradas por professores, alunos de graduação e pós-graduação e funcionários, pertencentes às mais diferentes áreas do saber. Elas atendem grupos comunitários que desejam trabalhar e produzir em conjunto, dando-lhes formação em cooperativismo e Economia Solidária e apoio técnico, logístico e jurídico para que possam viabilizar seus empreendimentos autogestionários (SINGER, 2002, p. 123).

Diante disso, percebe-se a importância das ITCP's para a sociedade como um todo, buscando sempre disseminar as características da economia solidária e uma vida melhor para todos.

A ITCP estudada neste trabalho foi a da Universidade Federal de São João del-Rei, a qual envolve vários empreendimentos, alunos, professores e funcionários.

\section{Incubadora Tecnológica de Cooperativas Populares da Universidade Federal de São João Del Rei (ITCP/UFSJ)}

A ITCP/UFSJ foi fundada em 1999 e, logo após, passou a integrar a Rede de ITCP's. Desde sua fundação, a ITCP/UFSJ desenvolve suas atividades baseada nas características da economia solidária, com o objetivo de alcançar a inclusão social e a geração de trabalho e renda.

A sede da ITCP/UFSJ localiza-se no Centro de Referência do Trabalhador (CRT), situado no Campus Tancredo de Almeida Neves (CTAN). O prédio possui salas de reunião, secretaria, cozinha e outras salas que são ocupadas por outros projetos da faculdade. Em sua estrutura, possui telefone, computadores, data show, câmera fotográfica, internet, impressora, entre outros recursos conquistados por meio de financiamento dos projetos.

No segundo semestre de 2016, a ITCP/UFSJ obteve o apoio da Prefeitura Municipal de Santa Cruz de Minas, do Programa de Apoio à Extensão da UFS e o financiamento do Programa Nacional de Incubadoras de Cooperativas Populares (PRONINC), cujos recursos são da Secretaria Nacional de Economia Solidária (SENAES) e do Ministério do Trabalho, recursos que foram intermediados pelo CNPq e utilizados na compra de equipamentos, em cursos de capacitação, material de consumo e bolsas para os discentes.

Nesse mesmo período, a incubadora conta com 22 discentes dos cursos de Administração, Ciências Contábeis, Ciências Econômicas, Engenharia de Produção, Engenharia 
Mecânica e Psicologia; dois docentes do Departamento de Engenharia Mecânica (DEMEC); um docente do Departamento de Ciências Administrativas e Contábeis (DECAC); e dois técnico-administrativos. Em reuniões semanais, na sede da ITCP, são discutidos vários assuntos que contribuem para o fortalecimento das atividades da incubadora, tais como informações sobre cada empreendimento incubado, propostas de ação e organização dos incubadores.

A ITCP é dividida em comitês, sendo eles os de secretaria, divulgação, financeiro, eventos e projetos. A secretaria é responsável pela emissão de certificados, preservação do material de consumo e arquivos de atas e de outros documentos. O comitê de divulgação é responsável pela manutenção do site e das redes sociais, buscando também novas formas de divulgar a incubadora. O comitê financeiro controla e presta as contas da ITCP/UFSJ. O comitê de eventos procura se informar sobre novos cursos e treinamentos para os membros da incubadora e para os empreendimentos. O comitê de projetos estuda novas fontes de financiamento.

Os empreendimentos incubados pela ITCP/UFSJ são os seguintes:

- São João del-Rei: Feira de Agricultura Familiar; AMERFS; Raízes da Terra; Meninas de Inhá; Meninas de São Sebastião da Vitória; Meninas do Zoeira; Congada São Dimas; Associação Arte \& Cia; ASAENFA; Feira de Economia Solidária; CENTURIART; BAYLEO; ASCAS e Cooperativa dos Catadores do Aterro Sanitário.

- Santa Cruz de Minas: COFESOL e Grupo de Artesãos.

- Prados: Feira de Agricultura Familiar; Salão de Beleza; Grupo de Artesanato de Pitangueiras; Grupo de Corte e Costura de Pitangueiras e Grupo de Corte e Costura do Bichinho.

- Barroso: CRIART; Mão na Massa; Delícias do Caeté e ASCAB.

- Coronel Xavier Chaves: Grupo de Corte e Costura; Grupo Cerdas Ecológicas; AMARCHA; Artesãos da Casa da Cultura; Cantina do Coreto e UNIARTE.

Para uma melhor organização, a ITCP/UFSJ é dividida em equipes que atuam em cada empreendimento e geralmente realizam visitas semanais. A metodologia de incubação observa a demanda de cada empreendimento, porém tem como base a estrutura apresentada no Quadro 1 (inserido na próxima página): 
Quadro 1 - Estrutura do processo metodológico para a incubação

\begin{tabular}{|c|c|c|c|}
\hline$\longrightarrow$ & $\begin{array}{c}\text { Fases ou Categorias } \\
\text { de ação }\end{array}$ & Atividades/técnicas & Observações \\
\hline \multicolumn{4}{|c|}{ Estágio de mobilização } \\
\hline \multirow[t]{2}{*}{ 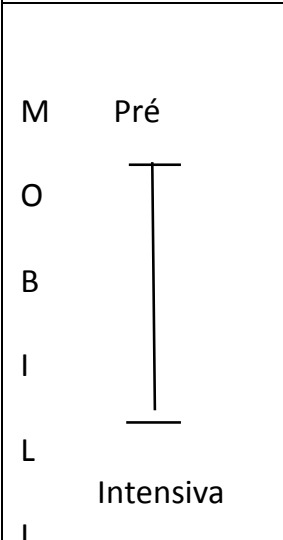 } & Caracterização & $\begin{array}{l}\text { Definição da origem da } \\
\text { demanda. Identificação do } \\
\text { grupo: seu perfil, suas } \\
\text { demandas, suas mobilizações } \\
\text { antecedentes. Utiliza } \\
\text { trabalhos de grupos para as } \\
\text { apresentações, discussões e } \\
\text { levantamentos. Elaboram-se } \\
\text { os instrumentos de previsão: } \\
\text { diagnósticos, programas, } \\
\text { projetos planos e outros } \\
\text { estudos. }\end{array}$ & $\begin{array}{l}\text { Fazem-se as apresentações } \\
\text { da ITCP e das pessoas do } \\
\text { grupo que demandam o } \\
\text { trabalho. Apresenta-se o } \\
\text { processo. São discutidos os } \\
\text { instrumentos elaborados e } \\
\text { tomadas as decisões. }\end{array}$ \\
\hline & & & \\
\hline \multirow{2}{*}{ 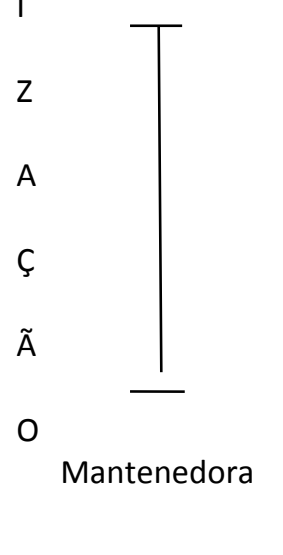 } & Organização & 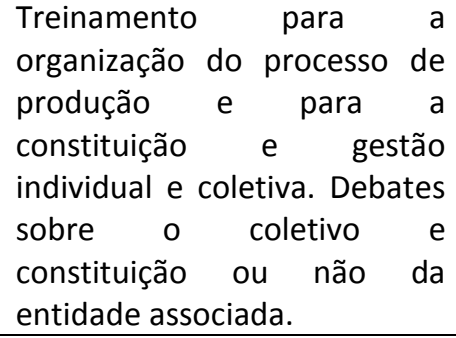 & $\begin{array}{l}\text { Quase sempre, } \\
\text { organização coincide com a } \\
\text { mobilização intensiva. }\end{array}$ \\
\hline & Ação Gestora & $\begin{array}{l}\text { Inicia-se quando se inaugura a } \\
\text { gerência do coletivo. }\end{array}$ & $\begin{array}{l}\text { Orienta-se pelos princípios e } \\
\text { formatos autogestores. }\end{array}$ \\
\hline
\end{tabular}

Fonte: Abreu (2007, p. 21).

Os empreendimentos incubados pela ITCP/UFSJ estudados neste trabalho foram a Associação de Catadores de Materiais Recicláveis de São João del-Rei (ASCAS) e a Associação dos Artesãos e Empreendedores de Economia Familiar (ASAENFA).

A ASCAS foi escolhida pelo fato de ser o empreendimento mais antigo incubado pela ITCP/UFSJ e pela proximidade dos seus associados e do seu contador, além de ter um histórico que permite aprofundar nas pesquisas. A ASAENFA foi escolhida por ser uma associação recente, e, com isso, permitir a identificação de como está atuando e como seus associados estão se organizando. 


\subsection{ASCAS}

A Associação de Catadores de Materiais Recicláveis de São João del-Rei (ASCAS) foi fundada em 2003 e está localizada na Rua Prefeito Lourival Gonçalves de Andrade s/no, Sítio Água Limpa, Bairro Vila Santa Terezinha. O aluguel do galpão é pago pela Prefeitura Municipal de São João del-Rei. A ASCAS foi criada com base na economia solidária e com o objetivo de garantir aos associados melhores condições de vida e inserção na sociedade, além de despertar nesses associados e na sociedade a preocupação com as questões ambientais e de preservação do meio ambiente.

Para facilitar o trabalho dos associados, foi criado, em 2007, um software para empreendimentos de catadores, o Catafácil. Este software foi desenvolvido por extensionistas da UFSJ e teve como objetivo resolver os problemas relativos ao controle de produção, de vendas e financeiros, promovendo autonomia aos catadores da ASCAS. O Catafácil, como o nome já diz, é de fácil aprendizagem. Os associados tiveram muitos esclarecimentos sobre o software, conseguindo manuseá-lo de maneira rápida. Com ele, é possível trabalhar de forma simples, ágil e transparente, além de aumentar a organização da associação. O Catafácil teve grande sucesso, e, com isso, seus desenvolvedores decidiram levá-lo a um maior número de cooperativas de catadores. O software se adequa a cada empreendimento.

No segundo semestre de 2016, a ASCAS contava com quatorze associados, os quais realizam a coleta e separação de materiais que atingem em média 15 toneladas por mês, para serem enviados à reciclagem. No ano de 2016, a associação passou a fazer parte da Rede Sul, que integra as associações de catadores de materiais recicláveis. Essa rede busca o melhor preço e promove a troca de informações e de experiências entre as associações. Com a participação da ASCAS na rede, houve o aumento da renda de seus associados.

As reuniões ocorrem de quinze em quinze dias, às sextas-feiras. Nas reuniões, são discutidas formas de melhor organização da associação, soluções de problemas apresentados, destinação do dinheiro da associação, entre outros assuntos. 


\subsection{ASAENFA}

O coordenador da Associação dos Artesãos e Empreendedores de Economia Familiar (ASAENFA), Roberto Lira, foi procurado em outubro de 2014 por um grupo de artesãos que queria realizar feiras de artesanato na cidade. As feiras foram concretizadas e, após o grupo perceber que elas tinham um grande público, houve uma reunião em março de 2015 para estruturar uma associação que fortalecesse ainda mais os trabalhadores, e, em maio de 2015, aconteceu a fundação da ASAENFA.

De acordo com Roberto Lira, a associação recebeu esse nome devido ao fato de ter outros ofícios que não apenas o artesanato, mas que também são apoiados pela economia solidária, como a economia familiar. Logo, a associação foi fundada para fortalecer o artesanato e também a economia familiar. Um dos objetivos da associação, segundo seu coordenador, é "mostrar que é possível para os trabalhadores que, quando eles procuram dar soluções isoladas para as suas dificuldades, fica difícil, aí eu mostrei para eles que, se nós trabalhássemos juntos, teríamos mais força para resolver as coisas que beneficiariam o coletivo, e aí a feira começou a crescer". Atualmente, as feiras acontecem de sexta-feira a domingo na Praça da Estação (Entrevista com Roberto Lira, 2017).

Para que as feiras pudessem acontecer, era necessária a aquisição de barracas. Assim, foi decidido em assembleia que alguns associados iriam a São Paulo comprá-las. A associação passou, então, a ter quinze barracas. Posteriormente, os associados descobriram que em São João del-Rei havia uma pessoa que fazia barracas iguais àquelas compradas em São Paulo. Foram adquiridas mais seis barracas, e a associação passou então a ter 21 barracas. No início de 2015, o coordenador fez um projeto para a Companhia de Desenvolvimento Econômico de Minas Gerais (CODEMIG), o qual solicitava recursos para a compra de mais 33 barracas. O projeto foi aprovado e atualmente a ASAENFA possui 54 barracas.

A associação se fortaleceu, e os associados perceberam que era importante ter um ponto fixo de vendas, surgindo, assim, a Casa do Artesão, localizada próxima à Igreja de Nossa Senhora do Rosário. O ponto da Casa do Artesão é de grande atração turística, e os 
trabalhadores conseguem uma boa geração de renda. Porém as feiras não deixaram de acontecer semanalmente.

A associação criou o Banco Comunitário, onde o dinheiro aplicado é fruto da mensalidade que os associados pagam para participar da associação e do aluguel pago para utilizarem as barracas na feira. $O$ banco oferece empréstimos a juros zero aos associados da ASAENFA para uso profissional, ou seja, para a compra de matérias-primas, equipamentos, ferramentas, etc.

No segundo semestre de 2016, a associação tinha em torno de cinquenta associados. Quando uma pessoa se associa, ela pode escolher fazer parte da feira, da Casa do Artesão, do Banco Comunitário ou dos três. As reuniões acontecem às terças-feiras na Casa do Artesão.

\section{Análise dos dados}

Este estudo foi de natureza exploratória, com o intuito de identificar a importância da ITCP/UFSJ, dos discentes da graduação de Ciências Contábeis e da contabilidade nos empreendimentos estudados. Além disso, buscou-se conhecer um pouco mais sobre a economia solidária e sobre as obrigações legais e fiscais desses empreendimentos.

Para a realização da pesquisa, foi aplicado um questionário, com questões abertas, para alguns associados dos empreendimentos estudados (ASCAS e ASAENFA) e para os contadores dos empreendimentos. Como a ASAENFA não possui contador, o questionário foi aplicado para o seu coordenador. A amostragem do número de associados para a aplicação do questionário foi determinada pelos $25 \%$ do número total de associados de cada empreendimento. A ASCAS possui quatorze associados, mas o questionário foi aplicado para quatro associados. A ASAENFA possui em torno de cinquenta associados, destes, treze responderam ao questionário. Na ASAENFA, o questionário foi aplicado para dez pessoas na feira e para três pessoas na Casa do Artesão.

Os quatro associados questionados na ASCAS começaram a fazer parte da associação entre 2006 e 2011. Dos treze associados da ASAENFA que responderam ao questionário, cinco estão na associação desde sua fundação, e oito entraram entre novembro de 2015 e agosto de 2016. 
Como foi citado, um dos objetivos da economia solidária é pensar no bem-estar da população e melhorar sua qualidade de vida. Em relação a essa questão, os associados foram questionados se a associação Ihes proporciona uma melhor qualidade de vida. De acordo com as respostas obtidas, percebe-se no Gráfico 1 que nos empreendimentos estudados a economia solidária alcança seu objetivo. Em relação aos dezessete associados que responderam ao questionário, $82,35 \%$ disseram que a associação lhes proporciona uma melhor qualidade de vida.

Dentre algumas explicações, estão ocupação do tempo, redução do estresse, amizade, geração de renda, trabalho com o que gosta e ajuda emocional. Os $17,65 \%$ restantes não chegaram a responder que a economia solidária não Ihes proporciona uma melhor qualidade de vida, mas alegaram que, em alguns momentos, a associação não atende às suas necessidades.

\section{Gráfico 1 - Qualidade de Vida}

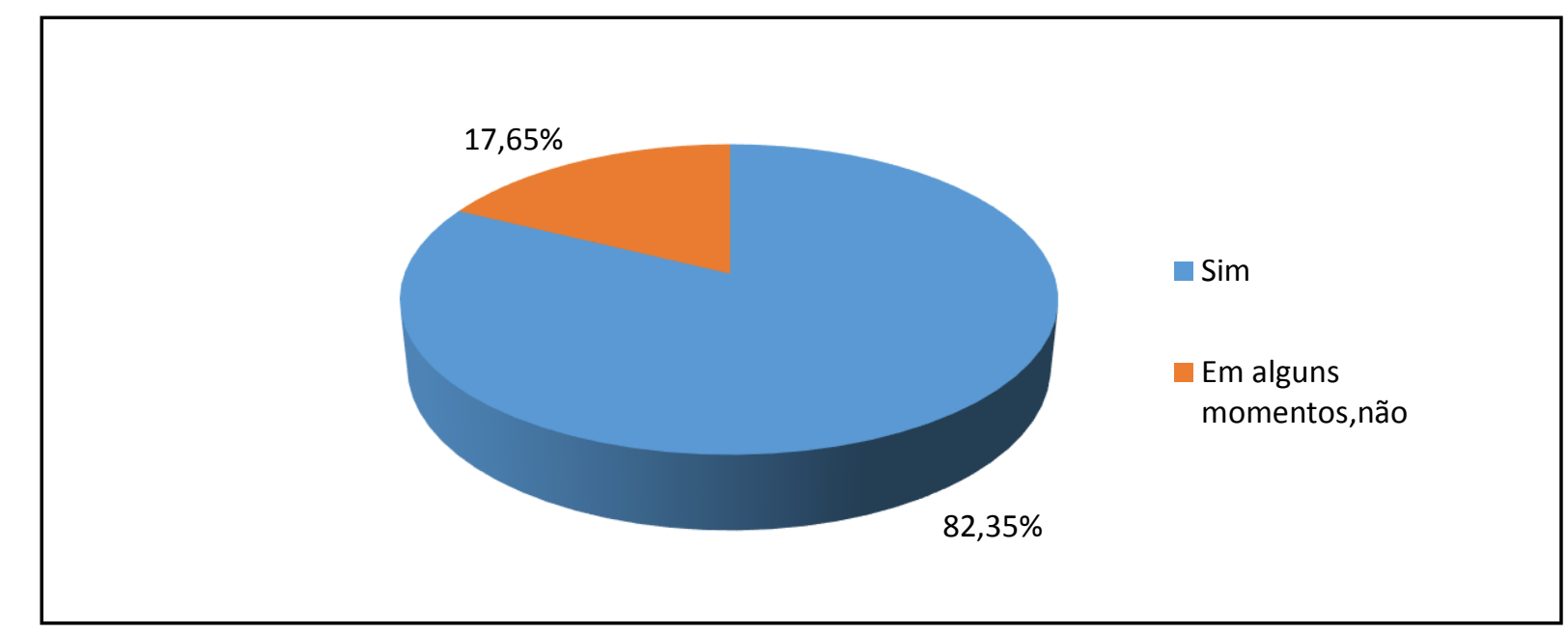

Fonte: Dados da Pesquisa (2016).

A maioria teve dúvida em relação à questão do conhecimento sobre economia solidária. Como pode ser visto no Gráfico 2, 47,06\% conhecem o termo, mas não conseguem defini-lo. A resposta mais obtida foi a de que "Um ajuda o outro" (29,41\%). Outras respostas que ajudaram na definição foram as seguintes: "Todos são um" (5,88\%), "Forma de criar projeto de renda" (5,88\%) e "Procura o bem-estar da população em geral" (5,88\%). Foram citados também o Banco Comunitário, que se tornou uma ajuda na geração de renda, e uma associada da ASAENFA que passa por problemas de saúde. Os outros associados, com o 
intuito de ajudá-la, decidiram montar para ela uma barraca na feira, sendo que cada um doou um produto dos que produz, e a renda dessa barraca é destinada à associada. Como se pode perceber, o termo Economia Solidária traz dúvidas aos associados, mas as associações procuram viver dessa nova economia.

\section{Gráfico 2 - Conhecimento sobre Economia Solidária}

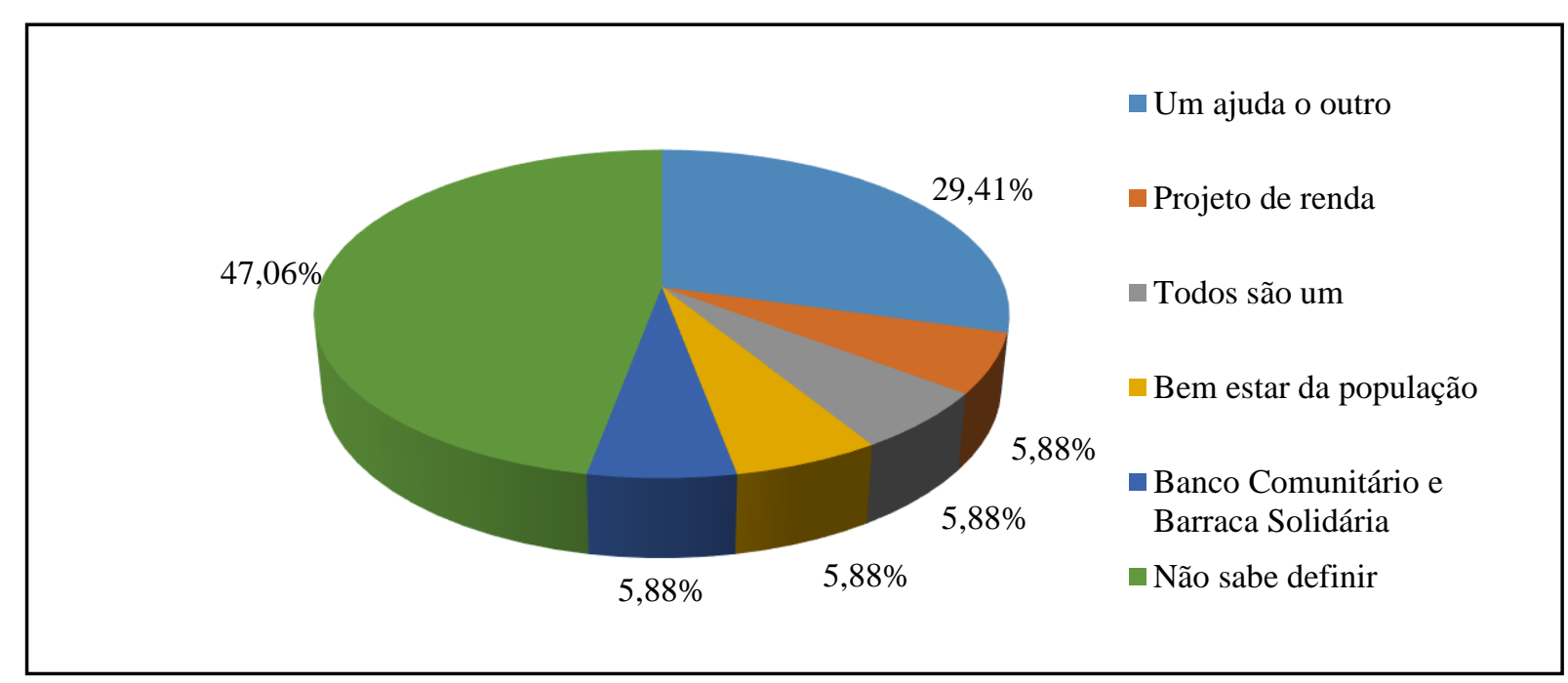

Fonte: Dados da Pesquisa (2016).

Em relação à participação de algum discente da graduação de Ciências Contábeis da ITCP/UFSJ, os associados da ASAENFA disseram que, no momento, não há discentes do curso acompanhando a associação, os que acompanharam eram do curso de Administração. No entanto, todos os associados responderam que, caso houvesse algum discente de Ciências Contábeis, poderia haver muita contribuição, como organização e controle da parte financeira, contribuição de alguém mais experiente, esclarecimento do que se passa na associação, auxílio no preço de vendas e contribuição para o fortalecimento da associação. Na ASCAS, há discentes de Ciências Contábeis que acompanham a associação, e, em relação à contribuição, eles afirmaram que os alunos ajudam muito, pois, quando precisam, estão dispostos a auxiliar, ajudando a resolver os problemas financeiros e explicando o que está acontecendo na associação.

A questão sobre a avaliação da participação da ITCP/UFSJ nas associações não foi respondida por todos. Pode ser visto no Gráfico 3 que 42,11\% não responderam a essa questão. Estão inseridos nesta porcentagem os questionados da ASAENFA, uma vez que a 
ITCP/UFSJ fez uma pausa no acompanhamento da associação, e muitos associados, por serem recentes, não tiveram contato com os discentes que fazem parte da ITCP/UFSJ. Mas tanto os associados da ASAENFA quanto os da ASCAS que responderam ao questionário avaliaram positivamente a ITCP/UFSJ. Dentre os motivos citados estão os de que os discentes possuem outra visão $(10,53 \%)$, transmitem conhecimento $(10,53 \%)$, não interferem diretamente $(5,26 \%)$, sabem ouvir $(5,26 \%)$, colocam seu ponto de vista $(5,26 \%)$ e têm interesse em ajudar (15,79\%).

O contador da ASCAS e o coordenador da ASAENFA também avaliaram a participação da ITCP/UFS nas associações. Eles deram uma avaliação positiva, e dentre os motivos alegados estão a boa vontade $(15,79 \%)$ e a frequência dos discentes às reuniões $(5,26 \%)$, os quais ajudam a ampliar a visão administrativa dos associados, levando-lhes novas possibilidades e novas formas de atuação. Com a avaliação positiva da ITCP/UFS por parte dos associados, do contador e do coordenador, percebe-se a importância do projeto que as universidades desenvolvem em Empreendimentos Econômicos Solidários e como estes são bem recebidos.

\section{Gráfico 3 - Avaliação da participação da ITCP/UFSJ}

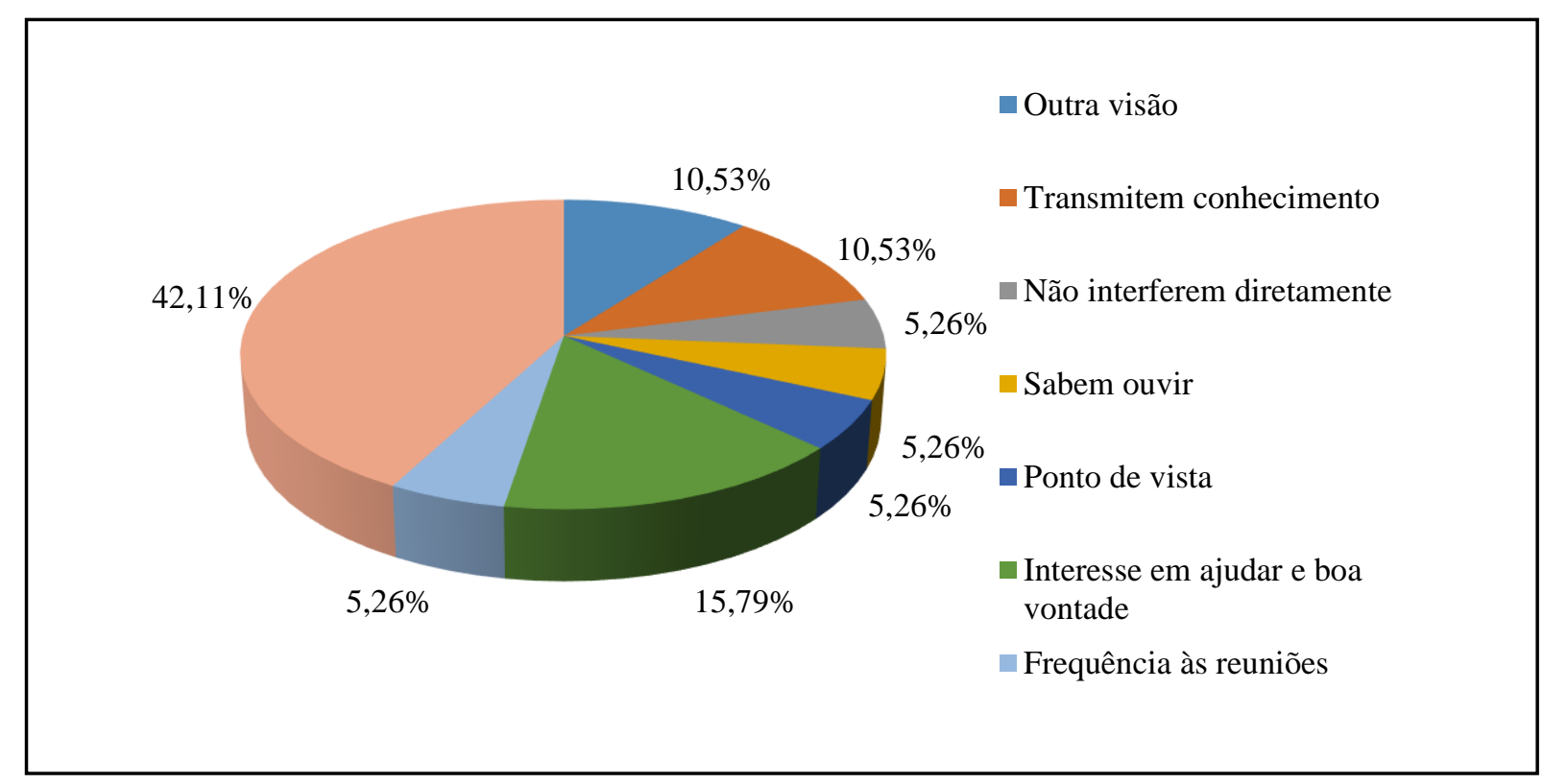

Fonte: Dados da Pesquisa (2016). 
Tanto na ASCAS como na ASAENFA, há um controle dos recursos recebidos e do que foi gasto, o que é um ponto positivo, porque mostra que eles se preocupam com o controle das finanças como forma melhor da associação se organizar. Uma questão que todos os associados da ASAENFA não sabiam é que, apesar da associação ser imune ou isenta de algumas obrigações, tem o dever de prestar declarações ao governo.

Então, com isso, eles também não souberam informar se a associação já precisou prestar alguma certidão negativa de débito para receber recursos. Na ASCAS, essa questão já era conhecida por todos, pelo fato de que, no ano de 2015, eles tiveram que regularizar a associação para poder cadastrá-la no programa Bolsa Reciclagem a fim de receber recursos. Esse programa é do Governo de Minas Gerais e visa incentivar financeiramente as associações de catadores de materiais recicláveis.

A presidente da associação na época fez uma consulta à Receita Federal e constatou a ausência da DIPJ do exercício de 2010 a 2014, da DCTF de 2010 a 2013 e da GFIP de dezembro de 2012 a janeiro de 2015. Os discentes da ITCP/UFSJ que acompanhavam a associação na época, com o consentimento dos associados, procuraram um contador que esclareceu toda a situação fiscal da ASCAS e que foi, logo após o pagamento da multa e a regularização da situação fiscal, contratado para acompanhar a associação. A multa gerada por essas obrigações acessórias em atraso foi de $R \$ 765,00$.

O último questionamento aos associados foi sobre a importância da contabilidade na associação. Todos deram avaliação positiva e acreditam que a contabilidade é fundamental $(63,16 \%)$, pois com ela há um maior controle $(15,79 \%)$, transparência $(10,53 \%)$ e cumprimento das obrigações (5,26\%), além de evitar complicações futuras $(5,26 \%)$.

A questão acima também foi respondida pelo contador e pelo coordenador. Ambos responderam que é fundamental. Afirmaram que por meio do registro de receitas e de despesas, os associados têm uma ideia clara da situação financeira da associação. Com a contabilidade, a entidade fica em dia com os órgãos públicos, mantendo-se em condições de receber recursos. O interessante no trabalho foi que, mesmo os associados não tendo muita ideia de como fazer a contabilidade, eles mostraram que suas respostas estão de acordo com o que profissionais da área pensam e buscam para o desenvolvimento das associações. 


\section{Gráfico 4 - Importância da Contabilidade}

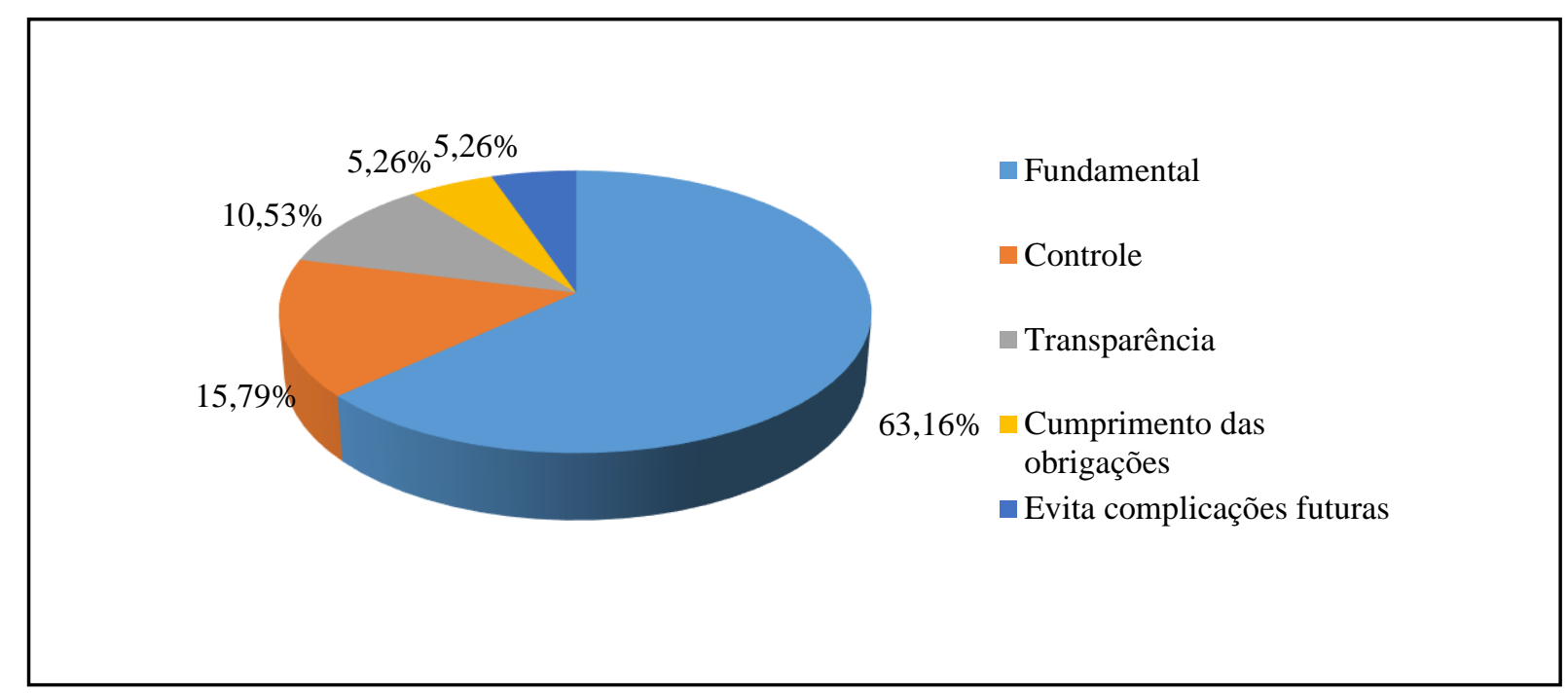

Fonte: Dados da Pesquisa (2016).

$\mathrm{Na}$ análise das partes legal e fiscal, verificou-se que a ASCAS e a ASAENFA estão em dia com todas as obrigações acessórias e certidões negativas de débito. O coordenador da ASAENFA é orientado por uma contadora sobre como fazer as declarações. As demonstrações contábeis não estão em dia nas duas associações. Na ASCAS, isso se deve ao fato de antes não haver um profissional para realizar o trabalho. O contador atual respondeu que, no ano de 2017, haverá geração das demonstrações contábeis, enfatizando que, infelizmente, essas demonstrações não são feitas pela maioria das associações. Na ASAENFA, essas demonstrações não estão em dia pelo fato de não haver contador.

\section{Considerações finais}

O presente estudo teve como intuito identificar a importância da ITCP/UFSJ, de discentes de Ciências Contábeis e da contabilidade nos Empreendimentos Econômicos Solidários (EES), além de trazer ideias sobre o termo economia solidária e sobre as obrigações legais e fiscais aplicadas aos EES.

Com o estudo, percebe-se que os associados entenderam essa nova forma de economia que foi citada pelos autores neste trabalho. Apesar do termo economia solidária 
trazer dúvidas, eles ajudam e são ajudados, buscando se inserir na sociedade e, com isso, melhorar sua qualidade de vida.

O estudo mostrou também a importância da ITCP/UFSJ para os empreendimentos incubados. Sua equipe se mostra muito prestativa e competente no que faz, trazendo uma visão da melhor maneira das associações se organizarem, além de construir laços com os incubadores. Este é um ponto muito positivo, pois as ITCP's como um todo buscam sempre a melhor forma de articulação, para que haja, além de empreendimentos desenvolvidos, incubadores e incubados com novas ideias e novas visões.

Destaca-se que as ITCP's buscam empreendimentos com capacidade de autonomia, ou seja, que os associados e os cooperativados sejam independentes para realizar a gestão em cada empreendimento. Para isso, no início, as ITCP's orientam os incubados, mas, depois, eles buscam formas de articulação para que ocorra o processo de desincubação. Neste processo, os incubadores deixarão de acompanhar os empreendimentos, mas com a certeza de que eles podem exercer suas atividades de maneira independente. Em alguns casos, esse processo é difícil e lento, pois os incubados ainda não têm capacidade de autonomia. Porém existem casos em que a desincubação é mais rápida e mais fácil. Portanto, este processo irá depender do desenvolvimento de cada empreendimento.

Os discentes de Ciências Contábeis foram muito bem avaliados pelos associados, e isso mostra que, mesmo não acompanhando a associação, no caso da ASAENFA, sempre é bom contar com pessoas mais experientes e que tragam novos conhecimentos. No caso da ASCAS, os discentes já se tornaram "obrigatórios" na associação, sempre prontos para ajudar e esclarecer o que for preciso. Com isso, pode-se identificar a importância da contabilidade para esses empreendimentos. Mesmo que muitos não saibam o que deve ser feito e quais as obrigações que devem ser entregues, eles sabem que a contabilidade é fundamental para que o empreendimento se encaminhe da melhor forma possível. O estudo mostrou também que os associados não têm um conhecimento do que a associação precisa para que a contabilidade esteja em dia, eles só se interessam por isso quando precisam de algum documento para receber recursos, como foi o caso da ASCAS.

Apesar da falta de conhecimento por parte dos associados, as obrigações acessórias e as certidões negativas de débito das associações estão em dia. Como a contabilidade é 
muito complexa, os associados não teriam noção sobre ela se não fosse essa participação da ITCP/UFSJ.

Mudanças estão ocorrendo na área contábil, e, se não houver um profissional acompanhando os EES, eles ficarão cada vez mais em débito com os entes federados. Com o desenvolvimento da tecnologia, é crescente o número de atividades que devem ser realizadas somente por meio do computador. O Sistema de Escrituração Digital das Obrigações Fiscais, Previdenciárias e Trabalhistas (e-social) é uma mudança que está ocorrendo na área contábil. Este é um projeto da Receita Federal do Brasil, do Ministério do Trabalho e Emprego, do Ministério da Previdência Social e da Caixa Econômica Federal. Esse projeto visa unificar as informações, de forma que as relevantes e as obrigações acessórias sejam realizadas em uma única entrega.

Para validar as informações via internet, é necessário o certificado digital, que visa proteger, trazendo mais segurança aos serviços eletrônicos. Para se ter um serviço de qualidade, precisa-se de um contador que esteja atualizado sobre as mudanças recentes na área contábil; sendo assim, percebe-se que a contabilidade está sendo cada vez mais imprescindível para os empreendimentos. Ela deve ser expandida nos EES para que todos saibam sua importância e tenham empreendimentos desenvolvidos e ausentes de débitos.

Um ponto de relevância para este estudo foi entender que a contabilidade, além de ser importante para um controle de receitas e de despesas, é essencial para que um empreendimento possa ser mantido, tenha sua fonte de renda e, com isso, melhore a qualidade de vida e o bem-estar dos associados, os quais são objetivos da economia solidária. Os pontos apresentados (ITCP's), economia solidária, Empreendimentos Econômicos Solidários, contabilidade, discentes de Ciências Contábeis, obrigações fiscais e legais) estão interligados e juntos buscam não só a inserção de trabalhadores excluídos, mas

novas formas destes se desenvolverem pessoal e profissionalmente, trazendo novas experiências e melhorando tanto a vida dos incubados como a dos incubadores.

\section{Referências}

ABREU, Jânio Caetano de. Cooperativismo Popular e Redes Solidárias (Org.) São Paulo: All Print, 2007. 
ALMEIDA, Edir Antônia de. Contabilidade e Autogestão - um estudo sobre a dimensão contábil nos processos de autogestão dos empreendimentos de economia solidária. 2006. Dissertação (Mestrado em Contabilidade - Faculdade de Economia, Administração e Contabilidade) - Universidade de São Paulo, São Paulo, 2006.

BOCAYUVA, P. Incubadora tecnológica de cooperativas populares da COPPE/UFRJ. In: CAMAROTTI, I.; PETER, S. (Orgs.). Redução da pobreza e dinâmica locais. Rio de Janeiro: FGV. 2001. p. 235-261.

BRASIL. Constituição Federal de 1988. Promulgada em 5 de outubro de 1988. Disponível em <http://www.planalto.gov.br/ccivil_03/constituicao/constituicao.htm>. Acesso em: 15 dez. 2016.

CAMPIGLIA, Américo Oswaldo. Introdução à hermenêutica das demonstrações contábeis. São Paulo: Atlas, 1997.

CTNSRF. Secretaria da Receita Federal. Código Tributário Nacional Disponível em: <http://www.planalto.gov.br/ccivil_03/leis/L5172Compilado.htm>. Acesso em: 16 dez. 2016.

IUDÍCIBUS, Sérgio de; MARION, José Carlos. Introdução à teoria da contabilidade: para o nível de graduação. 4. ed. São Paulo: Atlas, 2007.

MARION, José Carlos. Contabilidade empresarial. São Paulo: Atlas, 1998.

NASCIMENTO, Diogo T. do; OLAK, Paulo Arnaldo. As entidades sem fins lucrativos (terceiro setor) e as normas brasileiras de contabilidade aplicadas. In: XVI CONGRESSO BRASILEIRO DE CONTABILDADE. Goiânia: CFC, 2000.

OLIVEIRA, B. A. M.; ALVES, F. K. N.; PONTELO, T. C. As contribuições das incubadoras tecnológicas de cooperativas populares para o desenvolvimento da economia solidária e para a construção de um novo modelo de extensão universitária. In: Abreu, J. C. Cooperativismo popular e redes solidárias. São Paulo: All Print, 2007. p. 121-132.

SINGER, P. Introdução a economia solidária. São Paulo: Fundação Perseu Abramo, 2002. 